\title{
Game Playing Analysis of Planning and Supervision Collusion in Real Estate Land
}

\author{
Zhengfeng $\mathrm{Hu}^{*}$ and Kefeng Zhang*
}

Ningbo Institute of Technology, Zhejiang University, Ningbo 315100, China

\begin{abstract}
The development of a dynamic game model for planning a double and duplication of supervision based on the indeterminate appointment probability and order of supervisors on the grounds of the current causes of planning and supervision collusion in real estate land is presented in this paper and the question how to separate the planning from supervision availably is analyzed. The dynamic game is employed for the study. Results are as follows: First, feasibility and availability of planning a double (planning and supervision) are verified theoretically, which can reduce the monitoring cost. The higher the appointment probability of the second party of planning supervisors, the greater the risk pressure and moral remorse of the earlier planning supervisors. Thus, milder punishment is required to separate planning from supervision. Secondly, under planning and supervision, the earlier planning supervisors always dread supervision from the second party and the collusion probability with real estate developers is reduced. Therefore, the policy of planning and supervision should be vigorously marketed.
\end{abstract}

Keywords: Collusion, equilibrium analysis, land for real estate, planning and supervision.

\section{INTRODUCTION}

In recent years, there has been an increase in lawlessness in land use of real estate, which frequently arises and brings considerable influence [1]. In such lawlessness, illegal planning change plays a major part such as change of land use function, plot ratio adjustment, and building density adjustment [2]. Corruption cases of planning collusion in property market also frequently arise. For example, Zeng Hua, the former chief of planning Bureau in Kunming City was jailed for 13 years for taking bribes. In another case of Chongqing estate scandal in which 8 department officials from such departments as Land Departments and Planning Departments and on the others involved, the former director and the deputy director of Chongqing Planning Bureau abused their power for illegal adjustment of planning indexes of real estate developers to make excessive profits and obtain vast sums [3]. The lawlessness of land planning and supervision collusion causes great damage to city development, and disrupts sound development of real estate and land market, leading to loss of national assets and great harm to the interests of the pubic. Therefore, the matter should be brought to the forefront [4].

At present, there are few domestic studies on planning and supervision collusion in real estate land directly [5] focusing on the following aspects: firstly, serial cases of planning corruption are given as examples to figure out the characteristics, forms and influence of planning corruption. Causes are analyzed next and finally, countermeasures are put forward in the light of legal regulations.

*Address correspondence to these authors at the the Abo Akademi University, P.O. Box 311, FIN-65101 Vasa, Finland; Tel: +358-6-3247476; Fax:+358-6-3247457; E-mails: jan.saarela@abo.fi, fjalar.finnas@abo.fi
For example, Qian Ying [6] focused on four characteristics of planning corruption, that is, concealment, harmfulness, destructiveness, and being rich overnight, and provided suggestion regarding the aspects of law improvement and foreign experience for reference. Gong Yi [7] held the view that excessive administrative interference should be stopped to curb planning corruption. Wu Gaoqing [8] also elaborated characteristics of planning corruption by specific examples and believed that close cycle created a breeding ground for planning corruption. Secondly, few studies aimed at the introduction, comparative analysis and experience summary and popularization of actual practice of planning supervision in certain places. For instance, Zhou Xuandong [9] described the practical approach of plot ratio management in land for commercial use in Xuzhou city and summarized their experience for further popularization. Hou Jigong [10] and Chen Taiping [11] carried out a similar work. However, foreign studies of planning and supervision collusion which originated from Tirole $J$ [12] appeared much earlier. In this paper, the principle of prevention from collusion was presented as the theoretical basis for mechanism design of prevention from collusion. The principle states that any allocation result can be implemented by prevention of collusion. Later, literature of mechanism design of prevention of collusion and corruption elimination generally offered solutions from the following two aspects: the first solution is to change the contract between the client and the agent to reduce the corruption gains to further prevent it and the second one is to curtail the power of appointment between supervisors or government officials. The typical ones included Laffont and Meleu [13], Laffont and Martimort [14, 15] etc. They followed this thought pattern and pointed out that decentralized supervision and mutual monitoring and checking between officials can control planning corruption conveniently and 
can also enhance resource allocation efficiency. Domestic researches have been valuable for intensive study of planning and supervision in real estate land and foreign studies of collusion are helpful in expanding the research methods and paradigms. Nowadays, specific study of planning and supervision collusion in real estate land by game theory is currently prevailingTherefore, the problem of planning and supervision collusion in real estate land is chosen as the object of study in this paper and the dynamic game is employed to provide helpful reference for tackling planning corruption in real estate land.

\section{MATERIALS AND METHODS}

Generally speaking, the planned land use for real estate developers is large with 1000 or $1000 \mathrm{~m} 2$ as measurement unit. Currently with high property prices, great net profit per square meter can be acquired and thus the developers can adjust planning indicators such as building height, building plot ratio and building density etc., both privately and illegally. Taking the illegal adjustment of building plot ratio as an example, after its fine-tuning upward, huge profit measured in ten millions Yuan can be made by the developers. Illegal adjustment of other indicators is essentially the same and the distinction lies in different profits and concealments. It is the most direct and strongest internal power source for developers' private and illegal adjustment of planning indicators [16].

Simultaneously, under the current planning and supervision system, there is little public participation and great enforcement discretion of planning and supervision staff in government planning department being in a close cycle. Moreover, there is information asymmetry in the private information of developers' illegal adjustment for the planning and supervision staff, the public and other stakeholders such as property owners. The developers are absolutely the prevailing party and in general, it is very difficult for the public and such stakeholders as property owners to get hold of truthful information. Furthermore, profound professional knowledge is demanded for planning and supervision and thus the public and property owners usually have no means of supervision. Such realities prove to be the external incentives for collusion between supervisors and developers [17].

In addition, the existing punishment system for planning and supervision collusion corruption is far from perfect. Moreover, supervision frequency and success rate also require further improvement [18]. The cautionary cost of breaking the law for collusion participants also needs to be enhanced. For instance, the punishment for developers' illegal adjustment is much more in the form of administrative penalty. In short, with the influence of the above comprehensive factors, the the collusion of planning and supervision staff and developers is highly likely.

\section{GAME MODEL OF PLANNING AND SUPERVI- SION COLLUSION}

\subsection{Basic Assumption}

(1) In planning supervision, government planning department, real estate developers and planning supervision staff are all rational and risk-neutral. Planning and supervi- sion staff are delegated by government planning department to supervise the following planning of the developers and its actual utilization.

(2) Supposing that there is private and illegal fine tuning of planning indicators by developers (for example, the plot ratio is revised upward), as mentioned above, such adjustment is quite professional and deceiving, and common property owners can never know. Therefore, the tiny adjustment upward can bring huge illegal profit, which can be represented by $\mathrm{M}$, for the real estate developers. But under the supervision of planning and supervision staff, some false information (namely, information without adjustment) may be reported to them. In case the information is found out and reported to the government planning department (once their lawlessness is uncovered, the extraneous earnings of the developers, would be confiscated and also they would be punished by fine, which can be very costly for them.), developers would be willing to bribe the planning and supervision staff and the bribe can be represented by $\mathrm{H}$. Theoretically, the developers would bribe with all the extraneous earnings at most, and thus the formula $\mathrm{H} \leq \mathrm{M}$ can be obtained.

(3) Monitoring labour costs for planning and supervision staff are shown in $\mathrm{C}_{1}$. In case there is collusion between supervisors and real estate developers, the supervisors would be investigated and with the risk, they would endure certain pressure costs. Besides, as government workers, the job requires high work ethics. In the event of collusion, strong feelings of guilt can creep in due to personal work ethics, resulting in loss of utility. Thus, the risk pressure cost and possible moral remorse can be added up as S. The punishment for collusion between supervisors and real estate developers could be party discipline punishment, administrative penalties or legal penalties in the light of severity or detrimental effect. F is used to denote the punishment mechanism in this paper.

(4) To make the excitation mechanism perfect for supervisors, the reward as shown in $\mathrm{J}$, can be awarded to planning supervisors who provide truthful monitoring reports and unmask former supervisors' collusion with developers. As the reward is larger than the difference between bribe from real estate developers and loss of utility of supervisors, that is, $\mathrm{J}>\mathrm{H}-\mathrm{S}$, there will be no collusion. But certainly the reward can not be larger than the difference between added earnings of developers and loss of utility of two supervisors. However, supervisors and developers can collude to cheat for the reward, that is, $\mathrm{J} \leq \mathrm{M}-2 \mathrm{~S}$.

(5) The supervision ability of two assigned supervisors is defined equally: the same ability to find out personal information of real estate developers (usually their illegal adjustment of planning indicators) and the same probability, indicated by $\theta(\theta \in[0,1])$, of collusion with developers. It is assumed that the probability that the second supervisor will be delegated is $t \in[0,1]$, and the probability of government's informing of appointment order of supervisors is $\alpha \in[0,1]$.

\subsection{Order of Game Playing}

For the two appointed supervisors, the probability of being first appointed is $1 / 2$. Supposing that the first appointed one is $\mathrm{P}_{1}$, and the later one is $\mathrm{P}_{2}$, the expected order of game playing is shown in Fig. (1). 


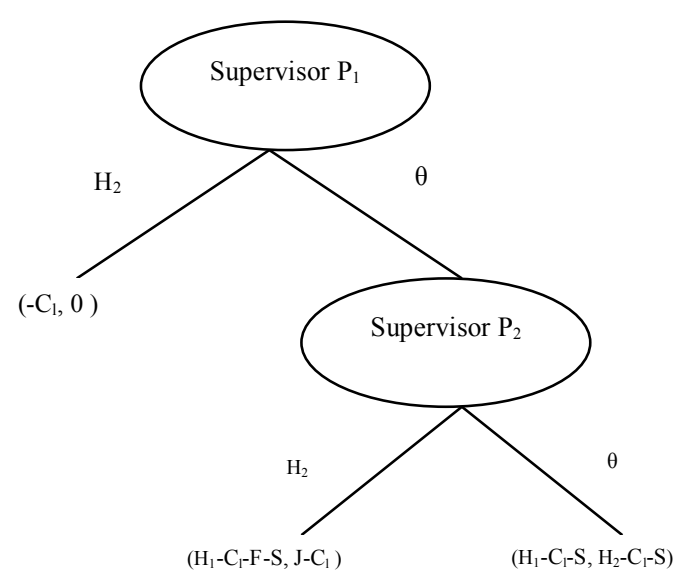

Fig. (1). Game playing order of supervisors.

After appointment, supervisor $\mathrm{P}_{1}$ may figure out developers' illegal information and thus bribers $\mathrm{H} 1$ are paid; If the bribes are rejected, and the illegal adjustment is reported to the government, the added earnings of developers will be confiscated and a fine will be given; if the bribes are accepted by supervisor $\mathrm{P}_{1}$, and the actual situation is hidden from the government, supervisor $\mathrm{P}_{2}$ will be delegated with a probability of $t$ and again bribers $\mathrm{H}_{2}$ will be paid by developers to $\mathrm{P}_{2}$. Supposing that bribers again are accepted by $\mathrm{P}_{2}$ and collusion forms, the earnings of $\mathrm{P}_{1}$ and $\mathrm{P}_{2}$ are $\mathrm{H}_{1}-\mathrm{C}_{1}-\mathrm{S}$ and $\mathrm{H}_{2}$ $\mathrm{C}_{1}-\mathrm{S}$ respectively. It is assumed that the bribes will be denied by $\mathrm{P}_{2}$ and the illegal adjustment will be reported, and reward $\mathrm{J}$ will then be awarded to the supervisor. But the supervisor $\mathrm{P}_{1}$, with bribers $\mathrm{H}_{1}$ from developers, will be punished with $\mathrm{F}$. On the other hand, P1 must also endure the loss of utility S due to risk pressure cost and moral remorse. The monitoring labour costs for two supervisors are all represented by $\mathrm{C}_{1}$. In addition, the added earnings of developers will be confiscated and a fine will be handed to them.

\subsection{Perfect Bayesian Equilibrium Analysis}

In the game model, bribes paid to supervisors are marked as $\mathrm{H}_{1}$ and $\mathrm{H}_{2}$. The appointment order can influence their strategic choice, that is, the choice whether to accept the bribes or not, which means if the monitoring strategies are given to one of supervisors, the other one will make the choice accordingly.

The probability of supervisor $\mathrm{P}_{1}$ 's assignment by government is $1 / 2$. Supervisor $P_{2}$ is later appointed with a probability of $t$ while there is collusion between $\mathrm{P}_{1}$ and developers. Thus, the probability of $\mathrm{P}_{2}$ 's assignment is $\theta t / 2$ and that of the assignment as supervisor is $(1+\theta t) / 2$. Based on the Bayes rule, the appointment order of planning and supervision staff is as follows:

the probability of $\mathrm{P}_{1}$

$\mathrm{q}(1)=1 / 2 \div(1+\theta t) / 2=1 /(1+\theta t)$

the probability of $\mathrm{P} 2$

$$
\mathrm{q}(2)=1-\mathrm{q}(1)=\theta \mathrm{t} /(1+\theta \mathrm{t})
$$

The expected cost, shown by ECr, for the supervisor's refusal of bribes is:
$\mathrm{ECr}=\mathrm{q}(1) \mathrm{C} 1+\mathrm{q}(2)(\mathrm{C} 1-\mathrm{J})=\mathrm{C} 1-\mathrm{J} \theta \mathrm{t} /(1+\theta t)$

It means that with $\mathrm{P}_{1}$ as the supervisor, the monitoring cost is $C_{1}$. However, with $P_{2}$ as the supervisor, besides $C_{1}$, reward $\mathrm{J}$ will be awarded to the supervisor for his exposure to collusion between $\mathrm{P}_{1}$ and developers. Thus the actual cost is reduced.

The expected cost for the supervisor's accepting of bribes, shown in $\mathrm{ECa}$, is:

$\mathrm{ECa}=\mathrm{q}(1)\{\mathrm{C} 1+\mathrm{S}-(1-\mathrm{t}) \mathrm{H} 1+\mathrm{t}[-\theta \mathrm{H} 1+(1-\theta)(\mathrm{F}-\mathrm{H} 1)]\}+\mathrm{q}$ (2) $(\mathrm{C} 1+\mathrm{S}-\mathrm{H} 2)=\mathrm{C} 1+\mathrm{S}-(\mathrm{H} 1+\theta \mathrm{t} \mathrm{H} 2) /(1+\theta \mathrm{t})+\mathrm{Ft}(1-\theta) /$ $(1+\theta \mathrm{t})$

There are two cases for the acceptance of bribes by supervisor $\mathrm{P}_{1}$. In the first case, as the bribes are rejected by the supervisor $\mathrm{P}_{2}$, punishment $\mathrm{F}$ is given to $\mathrm{P} 1$. In the other case, if the bribes are accepted by the supervisor $\mathrm{P}_{2}$, bribes $\mathrm{H}_{1}$ are also paid to the supervisor $\mathrm{P}_{1}$. With $\mathrm{P}_{2}$ as supervisor, and in case of his acceptance of bribes, the actual monitoring cost is reduced by $\mathrm{H}_{2}$ because of the bribes. The probability of $\mathrm{P}_{2}$ 's assignment as supervisor is marked as $t$. The supervisor suffering a loss, is shown by S. With $\mathrm{ECa}>\mathrm{ECr}$, the bribes from developers will be rejected by supervisors. From the formula (1) and (2), it can be obtained that:

$\mathrm{J} \theta \mathrm{t}>(\mathrm{H} 1+\theta \mathrm{t} \mathrm{H} 2)-\mathrm{Ft}(1-\theta)-1(1+\theta) \mathrm{t}$

In this case, a pure strategy to discuss $\theta=0$ or 1 is defined. Moreover, two kinds of equilibrium conditions with such pure strategy may arise. With $\mathrm{H}_{1}=\mathrm{H}_{2}$, same bribes will be obtained by the two supervisors and pooling equilibrium is established. With $\mathrm{H}_{1} \neq \mathrm{H}_{2}$, separated equilibrium is formed.

\subsubsection{Pooling Equilibrium Analysis}

When the supervisor $\mathrm{P}_{1}$ and $\mathrm{P}_{2}$ both believe that the other side will not accept bribes from developers, which means that $\theta=0$, there arises pooling equilibrium. It can be deduced from the formula (3) that

$\mathrm{H}<\mathrm{Ft}+\mathrm{St}$

This means that as the bribes reach a certain amount, the probability of supervisor $\mathrm{P}_{2}$ 's appointment is higher and it is much more possible for the supervisor $\mathrm{P} 1$ to be investigated and punished. It is a must that the supervisor suffers from greater risk and pressure as well as moral remorse. Thus the punishment $\mathrm{F}$ required to prevent pooling equilibrium of planning and supervision collusion becomes less and $\mathrm{F}$ is the least with dual regulation.

When both $\mathrm{P}_{1}$ and $\mathrm{P}_{2}$ expect that the other side will accept the bribes from developers, it can be inferred from the formula (3) that

$\mathrm{H}<\mathrm{t}(\mathrm{J}+2 \mathrm{~S}) /(1+\mathrm{t})$

Which means that for every planning supervisor, the bribes accepted from the developers are $\mathrm{Hmin}=t(J+2 S) /(1+t)$

Proposition 1: While the appointment order of the supervisors is not informed by the government, pooling equilibrium will arise in collusion.

Proposition proving: It is supposed that pooling equilibrium of collusion can be prevented and there is a hypothesis that $\mathrm{H} 1=\mathrm{H} 2=\mathrm{H}$. The incentive and restraint of developers are defined as $H+H t \leq M$, that is, $H \leq M /(1+t)$, and the bribes paid 
by developers are $H \max =\mathrm{M} /(1+\mathrm{t})$. For each supervisor, the bribes they are willing to accept are Hmin. With Hmax $<\mathrm{Hmin}$, pooling equilibrium of collusion can be prevented. In this case, a formula, $(\mathrm{J}+2 \mathrm{~S}) /(1+\mathrm{t})>\mathrm{M} /(1+\mathrm{t})$, can be obtained, that is, $\mathrm{M} /(\mathrm{J}+2 \mathrm{~S})<\mathrm{t} \leq 1$, which is in contradiction with the previous assumptions that $\mathrm{J}+2 \mathrm{~S} \leq \mathrm{M}, \mathrm{M} /(\mathrm{J}+2 \mathrm{~S})$ $\geq 1$. Thus, if the appointment order is not informed by the government, pooling equilibrium of collusion may arise.

\subsubsection{Separated Equilibrium Analysis}

Proposition 2: When the appointment order of supervisors is informed by the government, separated equilibrium of collusion will arise.

Proposition proving: If the bribes $\mathrm{H}_{2}$ from developers are greater than the reward $\mathrm{J}$ supervisors receive, and fully compensates for the risk pressure costs and moral remorse, the supervisor $\mathrm{P}_{2}$ will collude with the developers. If with $\mathrm{H}_{1} \geq \mathrm{S}$ and $\mathrm{H}_{2} \geq \mathrm{J}+\mathrm{S}$, for the supervisor $\mathrm{P}_{1}$, the optimal strategy is collusion. With the condition of incentive restraint of developers as $\mathrm{H}_{1}+\mathrm{H}_{2} \leq \mathrm{M}, J+2 \mathrm{~S} \leq \mathrm{M}$ can be obtained. To prevent collusion, formula $\mathrm{J}+2 \mathrm{~S}>\mathrm{M}$ is required, which is in contradiction with the previous assumption that $\mathrm{J}+2 \mathrm{~S} \leq \mathrm{M}$. So if the order of being excluded of supervisors is informed by the government, there may occur a separated equilibrium.

\subsection{Collusion-Preventing Analysis}

Proposition 3: If the probability of appointment order of the supervisor P2 is informed, the government can stop collusion equilibrium:

(1) With $\mathrm{J}>\mathrm{M} /[1+(1-\alpha) t]-\mathrm{S}$, the separated equilibrium of collusion can be prevented;

(2) With $\mathrm{J}>\max \{\mathrm{M} /(1+\mathrm{t}),[\mathrm{M}-(\mathrm{M}+\mathrm{F}) \alpha \mathrm{t}-\mathrm{S}[1+\mathrm{t}(1-\alpha)]] / \mathrm{t}(1-$ $\alpha)\}$ and $\mathrm{F}>\max \{(\mathrm{H}-\mathrm{S}) / \mathrm{t}$, $(\mathrm{H}-\mathrm{S})[1+\mathrm{t}(1-\alpha)] / \mathrm{t} \alpha-\mathrm{J}(1-\alpha) / \alpha\}$, the pooling equilibrium of collusion can be prevented.

Proposition proving(1): when separated equilibrium of collusion arises, with the rational constraints as $\mathrm{H}_{1} \geq \mathrm{S}, \mathrm{H}_{2} \geq \mathrm{J}$ $+\mathrm{S}$, the incentive constraints of developers are as follows:

(1) Developers have no motivation to inform the supervisor $\mathrm{P}_{1}$ of the order as $\mathrm{P}_{2}$, who demands the right of thein equation $\mathrm{H}_{1}+\mathrm{tH}_{2} \leq \mathrm{H}_{2}+\mathrm{tH}_{2}$ as the expected total sum of bribes while the supervisor $P_{1}$ is informed by developers of $P_{2}$ as being the planning supervisor. In this way, the bribes paid to $\mathrm{P}_{1}$ are also $\mathrm{H}_{2}$, and an inequation, $\mathrm{H}_{2} \geq \mathrm{H}_{1}$, can be calculated.

(2) Developers have no motivation to inform the supervisor $\mathrm{P}_{2}$ of the order as $\mathrm{P}_{1}$, which makes the left of the inequation $\mathrm{H}_{1}+\mathrm{H}_{2} \leq \mathrm{H}_{1}+(1-\alpha) \mathrm{H} 1+\alpha \mathrm{M}$, the total sum of bribes paid by developers while $\mathrm{P}_{1}$ and $\mathrm{P}_{2}$ are delegated as planning supervisors by the government. The right of the inequation is the bribes spent by developers when the supervisor $\mathrm{P}_{2}$ is informed of $\mathrm{P}_{1}$ as the planning supervisor and $\alpha \mathrm{M}$ means that when the supervisor $\mathrm{P}_{2}$ is informed of appointment order by the government, he does not collude with the developers and there are no added earnings $\mathrm{M}$ for the developers.

There comes $\mathrm{H}_{2} \leq(1-\alpha) \mathrm{H}_{1}+\alpha \mathrm{M}$.

As $\mathrm{H}_{2} \geq \mathrm{J}+\mathrm{S}$

So $\mathrm{H}_{1} \geq(\mathrm{J}+\mathrm{S}-\alpha \mathrm{M}) / 1-\theta$,
With the inequations, $\mathrm{tH}_{2} \geq \mathrm{t}(\mathrm{J}+\mathrm{S}), \quad \mathrm{M} \geq \mathrm{H} 1+\mathrm{tH}_{2}$, another inequation, $\mathrm{J} \leq \mathrm{M} /[1+(1-\alpha) \mathrm{t}]-\mathrm{S}$ can be obtained. With the inequation $\mathrm{J}>\mathrm{M} /[1+(1-\alpha) \mathrm{t}]-\mathrm{S}$, separated equilibrium of collusion can be prevented.

Proposition proving (2):

(1) With $\mathrm{H}_{1}=\mathrm{H}_{2}=\mathrm{J}$, developers' incentive constraint as $\mathrm{H}_{1}+\mathrm{tH}_{2} \leq \mathrm{M}$, there occurs $\mathrm{J} \leq \mathrm{M} /(1+\mathrm{t})$.

Thus when with $J>M /(1+t)$, the pooling equilibrium of collusion can be prevented.

(2) With $\mathrm{H}_{1}=\mathrm{H}_{2}=\mathrm{H}<\mathrm{J}$,

$$
\mathrm{J}>\max \{\mathrm{M} /(1+\mathrm{t}),[\mathrm{M}-(\mathrm{M}+\mathrm{F}) \alpha \mathrm{t}-\mathrm{S}[1+\mathrm{t}(1-\alpha)]] / \mathrm{t}(1-\alpha)\}
$$$$
\mathrm{F}>\max \{(\mathrm{H}-\mathrm{S}) / \mathrm{t},(\mathrm{H}-\mathrm{S})[1+\mathrm{t}(1-\alpha)] / \mathrm{t} \alpha-\mathrm{J}(1-\alpha) / \alpha\}
$$

The pooling equilibrium of collusion can be prevented.

Proposition proving as follows: it is supposed that "the planning supervisors' informing of orders" is termed as the event, g, and "non-informing" as the event, Ng. The probability of $P_{1}$ as the delegated planning supervisor is $q(1)$ $=1 /(1+\theta t)$ and that of $P_{2}$ is $q(2)=\theta t /(1+\theta t) . P\left(P_{1} \mid N g\right)$ and $\mathrm{P}\left(\mathrm{P}_{2} \mid \mathrm{Ng}\right)$ are the conditional probability with $\mathrm{P}_{1}$ 's and $\mathrm{P}_{2}$ 's non-informing of appointment order. By Bayes rule, it can be inferred that:

$$
\begin{aligned}
& \mathrm{P}\left(\mathrm{P}_{1} \mid \mathrm{Ng}\right)=\mathrm{P}\left(\mathrm{P}_{1} \times \mathrm{Ng}\right) / \mathrm{P}(\mathrm{Ng})=\mathrm{q}(1) /[\mathrm{q}(1)+\mathrm{q}(2) \\
& \alpha)]=1 /[1+\theta \mathrm{t}(1-\alpha)] \\
& \mathrm{P}\left(\mathrm{P}_{2} \mid \mathrm{Ng}\right)=1-\mathrm{P}\left(\mathrm{P}_{1} \mid \mathrm{Ng}\right)=\theta \mathrm{t}(1-\alpha) /[1+\theta \mathrm{t}(1-\alpha)]
\end{aligned}
$$

When the bribes from developers are refused by planning supervisors, (Z1)

$$
\mathrm{ECr}=\mathrm{P}\left(\mathrm{P}_{1} \mid \mathrm{Ng}\right) \mathrm{C} 1+\mathrm{P}\left(\mathrm{P}_{2} \mid \mathrm{Ng}\right)\left(\mathrm{C}_{1}-\mathrm{J}\right)=\mathrm{C}_{1}-\mathrm{J} \theta \mathrm{t}(1-\alpha) / 1+\theta \mathrm{t}(1-\alpha)
$$

As the bribes are accepted,

$\mathrm{ECa}=\mathrm{P}\left(\mathrm{P}_{1} \mid \mathrm{Ng}\right)\left\{\mathrm{C}_{1}+\mathrm{S}-(1-\mathrm{t}) \mathrm{H}+\mathrm{t}(1-\alpha)[-\theta \mathrm{H}+(1-\theta)(\mathrm{F}-\mathrm{H})]+\right.$ $\mathrm{t} \alpha(\mathrm{F}-\mathrm{H})\}+\mathrm{P}\left(\mathrm{P}_{2} \mid \mathrm{Ng}\right)(\mathrm{C} 1+\mathrm{S}-\mathrm{H})(\mathrm{Z} 2)$

The case whether the planning supervisors are informed of appointment orders is taken into consideration in the above formula. As with $\mathrm{H}_{1}=\mathrm{H}_{2}=\mathrm{H}<\mathrm{J}$, planning supervisor $\mathrm{P}_{2}$ will not collude with the developers. $\mathrm{Z} 2$.

$\mathrm{P}\left(\mathrm{P}_{1} \mid \mathrm{Ng}\right)$ and $\mathrm{P}\left(\mathrm{P}_{2} \mid \mathrm{Ng}\right)$ are substituted into the equation

$$
\begin{aligned}
& \text { By calculation, } \\
& \mathrm{ECa}=\mathrm{C} 1+\mathrm{S}-\mathrm{H}+\mathrm{tF}[1-\theta(1-\alpha)] /[1+\mathrm{t} \theta(1-\alpha)](\mathrm{Z} 3)
\end{aligned}
$$

The condition that the supervisors who are not informed of their appointment order do not collude with developers is: $\mathrm{ECa}|\theta=0 \geq \mathrm{ECr}| \theta=0$, then $\mathrm{F}>(\mathrm{H}-\mathrm{S}) / \mathrm{t}$.

The condition that the supervisor collude with developers is $\mathrm{ECa}|\theta=1 \leq \mathrm{ECr}| \theta=1$, then

$$
\mathrm{t}(1-\alpha) \mathrm{J} \leq(\mathrm{H}-\mathrm{S})[1+\mathrm{t}(1-\alpha)]-\mathrm{F} \alpha \mathrm{t}(\mathrm{Z} 4)
$$

By calculation,

$$
\mathrm{F} \leq(\mathrm{H}-\mathrm{S})[1+\mathrm{t}(1-\alpha)] / \mathrm{t} \alpha-\mathrm{J}(1-\alpha) / \alpha
$$

Thus with $\mathrm{F}>\max \{(\mathrm{H}-\mathrm{S}) / \mathrm{t},(\mathrm{H}-\mathrm{S})[1+\mathrm{t}(1-\alpha)] / \mathrm{t} \alpha-\mathrm{J}(1-\alpha) / \alpha\}$, collusion between planning supervisors and developers can be stopped. It can be drawn from (Z4) that the minimum 
bribes planning supervisors accept in collusion with developers are:

$$
\operatorname{Hmin}=[\mathrm{t}(1-\alpha) \mathrm{J}+\mathrm{F} \mathrm{t} \alpha] /[1+\mathrm{t}(1-\alpha)]+\mathrm{S}
$$

When the planning supervisor $\mathrm{P}_{2}$ is informed of appointment order, $\mathrm{P}_{2}$ does not collude with developers in the equation $\mathrm{H}_{2}<\mathrm{J}+\mathrm{S}$. However, the supervisor P1 may accept F, and developers will then lose the added earnings $M$ at least. At the moment, with personal rational constraint of developers as $H[1+t(1-\alpha)] \leq M(1-t \alpha)$, it can be concluded that the maximum bribe developers are willing to pay is Hmax $=$ M (1$\mathrm{t} \alpha) /[1+\mathrm{t}(1-\alpha)]$

Therefore, the prerequisite for preventing collusion between planning supervisors who are not informed of appointment orders and developers is $\mathrm{Hmax}<\mathrm{Hmin}$, then it can be drawn that:

$$
\begin{aligned}
& \mathrm{J}>[\mathrm{M}-(\mathrm{M}+\mathrm{F}) \alpha \mathrm{t}-\mathrm{S}[1+\mathrm{t}(1-\alpha)]] / \mathrm{t}(1-\alpha) \\
& \text { So with } \mathrm{J}>\max \{\mathrm{M} /(1+\mathrm{t}),[\mathrm{M}-(\mathrm{M}+\mathrm{F}) \alpha \mathrm{t}-\mathrm{S}[1+\mathrm{t}(1-\alpha)]] / \mathrm{t}(1- \\
& \mathrm{F}>\max \{(\mathrm{H}-\mathrm{S}) / \mathrm{t},(\mathrm{H}-\mathrm{S})[1+\mathrm{t}(1-\alpha)] / \mathrm{t} \alpha-\mathrm{J}(1-\alpha) / \alpha\}, \\
& \text { Pooling equilibrium of collusion can be prevented. }
\end{aligned}
$$
$\alpha)\}$,

\section{CONCLUSION}

In this paper, causes for planning and supervision collusion in real estate are analyzed, a dynamic game model is constructed and countermeasures based on game analysis are discussed in depth. Conclusions and suggestions can be drawn as follows:

First of all, the feasibility of planning a double and duplication of supervision is demonstrated theoretically. Planning and supervision system helps to prevent collusion between planning supervisors and real estate developers, and also reduces the punishment and supervision costs spent in preventing collusion. The higher the probability of the second party of planning and supervision' being delegated, the greater the risk of the previous supervisors' being investigated and punished and larger is their risk pressure cost and also greater is their moral remorse. Thus, the corresponding punishment can be milder.

Secondly, with appropriate punishment and incentive mechanism, the mutual monitoring of the two parties of planning supervisors' is much better and thereby, the probability of their collusion with developers drops. The previous supervisor dreads supervision from the later supervisors and the probability of their collusion with developers can be reduced. The function of the second party of planning supervisors should be put into full play in order to prevent planning and supervision collusion.

Thirdly, currently in towns and countries of China, a system for planning and supervision has been established, the core of which is supervision of urban and rural planning implementation in local areas by sending out planning supervisors from government of higher authorities to the subordinate ones. By August of 2012, by strict selection of Ministry of Housing and Urban-Rural Development (MOUURD) step by step, one hundred and two urban and rural planning supervisors have been sent and stationed in 89 cities. So far, planning supervisors have been sent out to the four munici- palities directly under the Central Government. The MOHURD has stated that more efforts will be made to strengthen their supervision. Meanwhile, provincial-level planning and supervision system has been established one after the other throughout the provinces and by August of 2012, the system had been introduced in 19 provinces. It can be argued that substantially planning and supervision system is planning a double and duplication of supervision. The planning supervisors can be granted second party supervision and they can supervise the local planning supervisors effectively to stop collusion between real estate developers. Since the implementation of planning and supervision system, cases of planning collusion have been decreasing annually, which clearly verifies the feasibility and effectiveness of double planning and supervision system for preventing planning collusion.

Lastly, in addition to vigorous promotion and implementation of planning and supervision system, for better prevention of planning collusion, the administrative strength and range of supervision on planning supervision subjects (organizations and personnel) should be enhanced. Compulsory constraints of rigid laws and regulations should be reinforced and punishment mechanism should be improved. As the punishment for participants in planning collusion is intensified, the cost for collusion will be increased, which truly can be a warning and deterrent. Moreover, the incentive mechanism of planning and supervision subjects should be improved. In this way, on one hand, the bribery cost of subjects who offer bribes will increase and on the other hand, the supervisors will be motivated and their supervision will be more effective. It is equally important to promote planning and supervision ability of the public and enhance their engagement in supervision.

\section{CONFLICT OF INTEREST}

The authors confirm that this article content has no conflict of interest.

\section{ACKNOWLEDGEMENTS}

This work is supported by the National Natural Science Foundation of China (Grant No.: 51379187).

\section{REFERENCES}

[1] Z. Y. Xie, "Game Theory in Economy," University Publishing House, 2010, pp. 267-272.

[2] J. Zhen, and Q. Han, "To prevent conflicts of interest: Effective way of corruption management in real estate industry". China Real Estate, vol. 8, pp. 75-78, 2011.

[3] "Investigation of cases of real estate in chongqing" $<$ http://news.xinhuanet.com/legal/2008/10/13/content10185872. htm>

[4] J. Cui, "Reasons why urban constitutions are abused", People's Daily, 21st May,14th edition, 2008.

[5] H. J. Li, "Public paticipation in urban planning of shaoyang city. Xiangtan University, vol. 06, no. 10, pp. 21-22,30, 2008.

[6] Y. Qian, and Y. Lao, "Punishment for planning corruption", Government Legality, vol. 8, pp. 13-14, 2007.

[7] Y. Gong, "Effective measures to stop planning corruption", People's Tribune, vol. 01, pp. 26-27, 2005.

[8] G. Q. Wu, and C. Xie, "Close cycle as breeding ground of planning corruption", Procuratorial Daily, 14th June, 007th edition, 2011. 
[9] X. D. Zhou, "Planning and management of plot ratio in land for commercial use in xuzhou city", Jiangsu Urban Planning, vol. 4, pp. 39-41, 2010.

[10] J. G. Hou, "Supervision and strategies of building area and plot ratio after approval", Jiangsu Urban Planning, vol. 12, pp. 12-13, 2010.

[11] T. P. Chen, "Standardized management of plot ratio and treatment of urban planning corruption", Jiangsu Urban Planning, vol. 9, pp. $17-18,2007$.

[12] J. Tirole, "Hierarchies and bureaucracies: On the role of collusion in organization", Journal of Law, Economics and Organizations., vol. 2, no. 2, pp. 181-214, 1986.

[13] J. J. Laffont, and M. Mathieu, "Reciprocal supervision, collusion and organizational design", Scandinavian Journal of Economics, vol. 99, no. 4, pp. 519-540, 1997.
[14] J. J. Laffont, and D. Martimort, "Collusion and delegation", The RAND Journal of Economics, vol. 29, no. 2, pp. 280-305, 1998.

[15] J. J. Laffont, and D. Martimort, "Separation of regulators against collusive behavior". The RAND Journal of Economics, vol. 30, no. 2, pp. 232-262, 1999.

[16] D. J. Liu, "Defect of supervision mechanism in urban construction planning". Economic Information Daily, 30th Mar, 001st edition, 2006.

[17] J. J. Huai, X. M. Liu, and H. M. Lei, "Game analysis of noncooperative bargaining between the local government and the land agent”, Operations Research and Management Science, vol. 6, no. 3, pp. 71-74, 2008.

[18] Z. C. Liu, "Intervention of three ministries in supervision of plot ratio in property market and multiple supervision of real estate development". China Business News, 8th Dec, A15, 2009.

Received: June 10, 2015

Revised: July 29, 2015

Accepted: August 15, 2015

(C) Hu and Zhang; Licensee Bentham Open.

This is an open access article licensed under the terms of the (https://creativecommons.org/licenses/by/4.0/legalcode), which permits unrestricted, noncommercial use, distribution and reproduction in any medium, provided the work is properly cited. 